\title{
Kinetic studies of novel inhibitors of endomorphin degrading enzymes
}

\author{
Renata Perlikowska $\cdot$ Jakub Fichna $\cdot$ \\ Jean Claude do-Rego $\cdot$ Katarzyna Gach • \\ Anna Janecka
}

Received: 29 June 2010/Accepted: 7 May 2011/Published online: 20 May 2011

(c) The Author(s) 2011. This article is published with open access at Springerlink.com

\begin{abstract}
Endomorphins (EMs), two endogenous $\mu$-opioid receptor selective ligands, are attractive lead compounds for opioid-based pain management studies. However, these peptides are quickly degraded by peptidases, in particular by dipeptidylpeptidase IV (DPP IV) and aminopeptidase M (APM). Targeting enzymatic degradation is one approach to prolong endomorphin activity. In this study we characterized the action of two new inhibitors of similar to endomorphins structure, Tyr-Pro-Ala- $\mathrm{NH}_{2}$ (EMDB-2) and Tyr-Pro-Ala-OH (EMDB-3), which were designed earlier in our laboratory. The presented data give evidence that EMDB-2 and EMDB-3 are potent inhibitors of enzymes responsible for endomorphin cleavage. These compounds are stable and easily synthesized. EMDB-2 and EMDB-3 are competitive inhibitors of both, DPP IV and APM, with $K_{\mathrm{i}}$ values in micromolar range. They are less potent than diprotin A in protecting EMs against DPP IV but more potent than actinonin in protecting these peptides against APM.
\end{abstract}

R. Perlikowska · J. Fichna $\cdot$ K. Gach · A. Janecka ( $₫)$

Department of Biomolecular Chemistry, Medical University of Lodz, Mazowiecka 6/8, 92-215 Lodz, Poland

e-mail: anna.janecka@umed.lodz.pl

\section{J. C. do-Rego}

Institut Fédératif de Recherches Multidisciplinaires sur les Peptides (IFRMP 23), Laboratoire de

Neuropsychopharmacologie Expérimentale, Faculté de

Médecine et Pharmacie, Université de Rouen, EA 4359,

Rouen, France

J. C. do-Rego

Centre National de la Recherche Scientifique (CNRS),

Rouen, France
Keywords Enzymatic degradation ·

Dipeptidylpeptidase IV · Aminopeptidase M ·

Inhibition constant

\section{Introduction}

At present, the treatment of severe pain relies mostly upon administration of centrally acting opiates such as morphine and its surrogates, which target $\mu$-opioid receptors in the brain. In spite of the powerful in vivo efficacy of these drugs, their long-term use is limited by a number of well-known side-effects, including tolerance, physical dependence, respiratory depression, and diverse gastrointestinal effects. Discovery of endogenous $\mu$-opioid receptor ligands, endomorphin-1 (EM-1, Tyr-Pro-Trp-Phe- $\mathrm{NH}_{2}$ ), and endomorphin-2 (EM-2, Tyr-Pro-Phe-Phe- $\mathrm{NH}_{2}$ ) more than a decade ago (Zadina et al., 1997) initiated extensive studies on the possible use of these peptides as analgesics instead of morphine. EMs exhibit outstanding potencies towards both, acute and chronic neuropathic pain, as was demonstrated in rodents in various types of pain tests (Narita et al., 1999; Horvath et al., 1999; Horvath, 2000; Przewłocki and Przewłocka, 2001; Grass et al., 2002). Furthermore, potentially advantageous pharmacological properties of EMs are the possible dissociation of analgesic and rewarding effects in the rat (Wilson et al., 2000) and the moderate respiratory depression when compared with morphine (Czapla et al., 2000; Fichna et al., 2007). However, the main limitations of the use of EMs as analgesics are short duration of action and lack of activity after oral administration, both due to the poor metabolic stability of these peptides (Shane et al., 1999; Tomboly et al., 2002). Applying chemical modifications to the structure of EMs is one strategy to obtain compounds with desired pharmacological profile. 
Another strategy might be increasing the level of endogenous EMs by the use of peptidase inhibitors. The enzyme which is primarily involved in the first cleavage step of EMs is a serine peptidase, dipeptidyl peptidase IV (DPP IV), which liberates Tyr-Pro dipeptides from amino terminus of EMs (Mentlein, 1999; Tomboly et al., 2002). Proline-specific aminopeptidase M (APM) further splits the obtained fragments of EMs (Sakurada et al., 2003) (Fig. 1).

Degradation of EMs can be significantly blocked by protease inhibitors. The most often used inhibitors of DPP IV are tripeptides Ile-Pro-Ile (diprotin A) and Val-Pro-Leu (diprotin B) (Mentlein, 1999). The action of APM is inhibited by actinonin (Sugimoto-Watanabe et al., 1999; Tomboly et al., 2002). Sakurada et al. (2003) showed that simultaneous administration of EM-2 and diprotin A to the mouse brain resulted in a fivefold longer duration of analgesic action compared with EM-2 alone. Actinonin significantly blocked EM-1 degradation in rat spinal cord homogenate (Sugimoto-Watanabe et al., 1999).

In the search for effective blockers of EM degrading enzymes, we have synthesized several tri- and tetrapeptides with similar to EMs structure but with low $\mu$-opioid receptor affinities and tested them as possible inhibitors. Two of these peptides, Tyr-Pro-Ala- $\mathrm{NH}_{2}$ (EMDB-2) and Tyr-Pro-Ala-OH (EMDB-3), turned out to be effective blockers of EM degradation by rat brain homogenate (Fichna et al., 2006). The action of these two tripeptides was further investigated in rat ileum in vitro (Fichna et al., 2010). They both significantly prolonged the inhibitory effect of EM-2 on smooth muscle contractility in rat ileum.

The aim of this study was to investigate how these tripeptides influence enzymatic cleavage of EMs by purified enzymes, DPP IV and APM, and what type of inhibition they represent.

\section{Materials and methods}

Peptide synthesis

Peptides were synthesized by a solid phase method on MBHA Rink amide resin for C-terminally amidated analogs and on Wang resin for peptide acids, using Fmoc
EM-1

Tyr-Pro-Trp-Phe-NH2

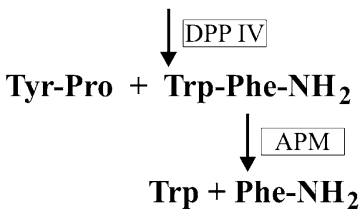

EM-2

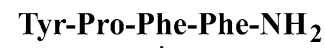
1 DPP IV

Tyr-Pro + Phe-Phe-NH

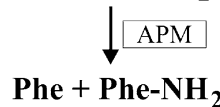

Fig. 1 Scheme of EM metabolism in the brain strategy and were purified by HPLC, as described earlier (Fichna et al., 2006).

Determination of EM degradation rates

The degradation studies were performed using pure, commercially available enzymes. DPP IV was used at a concentration of $0.002 \mathrm{mg}$ protein $/ \mathrm{ml}$ and APM at a concentration of $0.06 \mathrm{mg}$ protein $/ \mathrm{ml}$. Solutions of EMs and inhibitors were made by dissolving them in Tris- $\mathrm{HCl}$ buffer $(50 \mathrm{mM}, \mathrm{pH} 7.4)$ to obtain $1 \mathrm{mM}$ concentrations. Enzymes, EMs and inhibitors were incubated over 0, 7.5, $15,22.5$, and $30 \mathrm{~min}$ at $37^{\circ} \mathrm{C}$ in a final volume of $200 \mu \mathrm{l}$. The reaction was stopped at the required time by placing the tube on ice and acidifying with $20 \mu \mathrm{l}$ of $1 \mathrm{M}$ aqueous $\mathrm{HCl}$ solution. The aliquots were centrifuged at $20,000 \times g$ for $10 \mathrm{~min}$ at $4^{\circ} \mathrm{C}$. The obtained supernatants were filtered over Millipore Millex-GV syringe filters (Millipore) and analyzed by RP-HPLC on a Vydac $\mathrm{C}_{18}$ column $(5 \mu \mathrm{m}, 4.6 \mathrm{~mm} \times 250 \mathrm{~mm})$, using the solvent system of $0.1 \%$ TFA in water (A) and $80 \%$ acetonitrile in water containing $0.1 \%$ TFA (B) and a linear gradient of 0-100\% B over $25 \mathrm{~min}$. Three independent experiments for each assay were carried out in duplicate. The rate constants of degradation $(k)$ were obtained as described earlier (Tomboly et al., 2002), by the least square linear regression analysis of logarithmic endomorphin peak areas $\left(\ln \left(A / A_{O}\right)\right.$, where $A$ the amount of peptide remaining, $A_{0}$ initial amount of peptide versus time. Degradation halflives $\left(t_{1 / 2}\right)$ were calculated from the rate constants as $\ln 2 / k$.

Measurement of inhibition of proteolytic activity of DPP4 and APM

The inhibitory potency of each inhibitor was determined at five concentrations of substrate $(1.25,0.625,0.25,0.125$, and $0.0625 \mathrm{mM})$. Reaction was initiated by addition of enzyme (DPP IV or APM) to solution containing substrate (EM-1 or EM-2) and inhibitor (EMDB-2 or EMDB-3). In each case, the reaction was allowed to proceed at $37^{\circ} \mathrm{C}$ for $0,7.5,15,22.5$, and $30 \mathrm{~min}$ as described in a previous section.

Statistical analysis

Statistical and curve-fitting analyses were performed using Prism 4.0 (GraphPad Software Inc.). The data are expressed as means \pm SEM. Differences between groups were assessed by one-way analysis of variance (ANOVA), followed by Student-Newman-Keul's test.

Values of percentage inhibition of EM degradation were calculated using following formula, which was described earlier (Tomboly et al., 2002): 
Inhibition $(\%)=\left(k_{0}-k_{\mathrm{i}}\right) / k_{0} \times 100$,

where $k_{0}$ the rate constant of degradation without inhibitor, $k_{\mathrm{i}}$ the rate constant of degradation with inhibitor.

\section{Results}

Effect of inhibitors on degradation of EMs by DPP IV

We evaluated EMDB-2 and EMDB-3 for their inhibitory effect on degradation of EMs by DPP IV. Diprotin A was included in the study for comparison. Degradation of EMs was analyzed by reversed phase HPLC. Effects of $30 \mathrm{~min}$ incubation of EM-2 with DPP IV in the absence and presence of inhibitors are shown in Fig. 2. The chromatographic peak area of EM-2 was found to decrease greatly in the sample without inhibitors. Diprotin A almost completely suppressed enzymatic cleavage of EM-2, while EMDB-2 and EMDB-3 only partially protected EM-2 against hydrolysis. Degradation rates and half-lives of EMs alone and in the presence of inhibitors are collected in Table 1. Different rates of degradation of EM-1 and EM-2 by DPP IV were observed. EM-1 was about 1.5 times more resistant to DPP IV than EM-2, which is in agreement with the data obtained by others (Tomboly et al., 2002; Grass et al., 2002; Fujita and Kumamoto, 2006; Keresztes et al., 2010). EMDB-2 and EMDB-3 increased EM-1 and EM-2 half-lives two- to threefold. The effects of inhibitors on degradation of EMs after 30 min incubation with DPP IV
Fig. 2 Effect of inhibitors on the degradation of EM-2 by DPP IV. The reaction mixture was incubated at $37^{\circ} \mathrm{C}$ for $30 \mathrm{~min}$ in the absence (a) and presence of diprotin $\mathrm{A}(\mathbf{b})$, EMDB-2 (c), and EMDB-3 (d). Asterisk indicates the peak derived from the inhibitor added

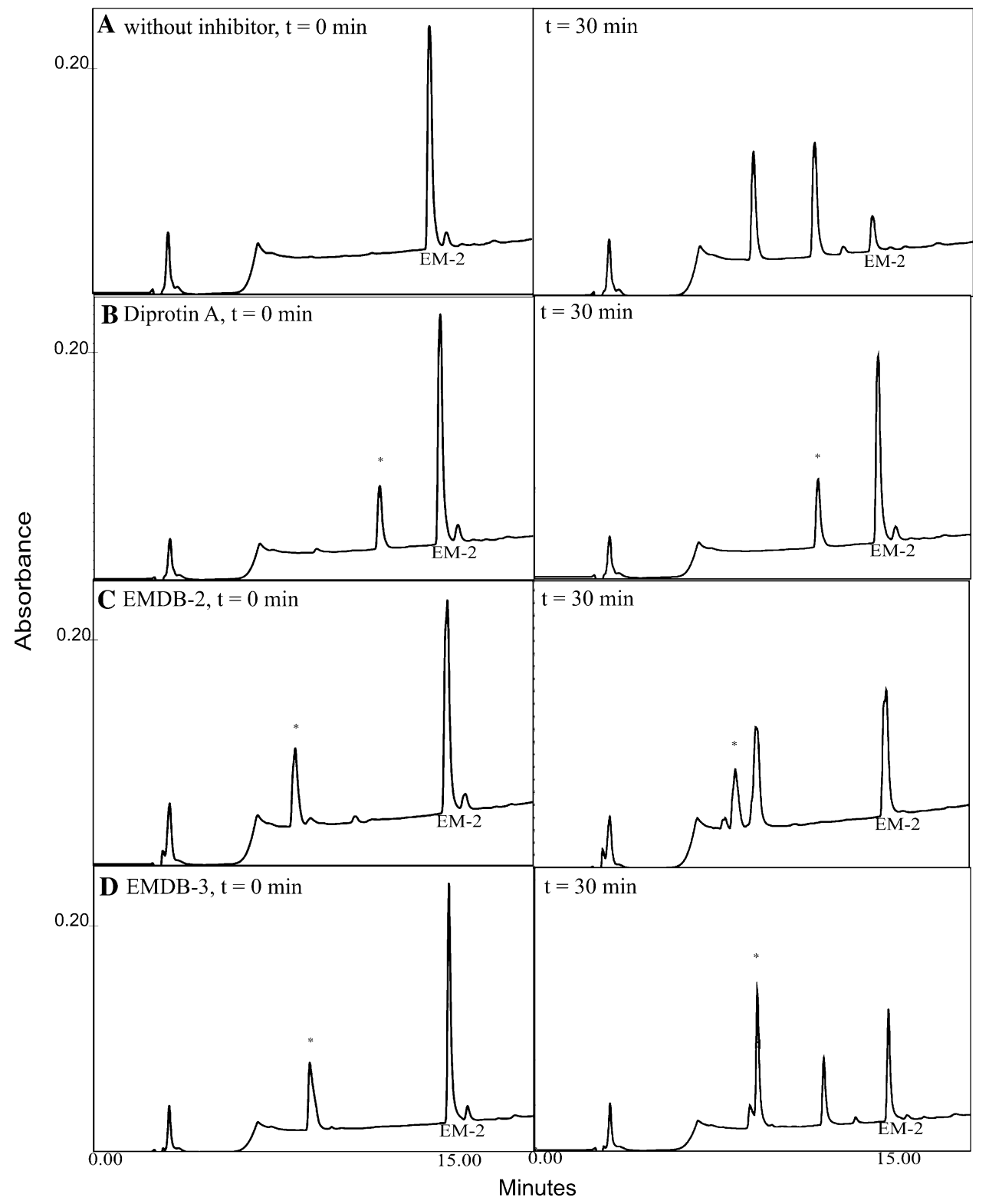


Table 1 Degradation rates $(k)$ and half-lives $\left(t_{1 / 2}\right)$ of EMs incubated with DPP IV alone and in the presence of inhibitors

\begin{tabular}{|c|c|c|c|c|}
\hline \multirow[t]{3}{*}{ Inhibitor } & \multicolumn{4}{|l|}{ DPP IV } \\
\hline & \multicolumn{2}{|l|}{ EM-1 } & \multicolumn{2}{|l|}{ EM-2 } \\
\hline & $100 \times k(1 / \mathrm{min})$ & $t_{1 / 2}(\min )$ & $100 \times k(1 / \mathrm{min})$ & $t_{1 / 2}(\min )$ \\
\hline Without inhibitor & $4.12 \pm 0.2$ & $16.7 \pm 0.52$ & $6.30 \pm 0.31$ & $10.9 \pm 0.64$ \\
\hline Diprotin A & $0.13 \pm 0.01$ & $530 \pm 14.5 * * *$ & $0.18 \pm 0.01$ & $383 \pm 20.2 * * *$ \\
\hline Tyr-Pro-Ala-NH ${ }_{2}$ (EMDB-2) & $3.02 \pm 0.09$ & $22.9 \pm 1.14 *$ & $3.48 \pm 0.13$ & $19.8 \pm 0.75^{*}$ \\
\hline Tyr-Pro-Ala-OH (EMDB-3) & $2.51 \pm 0.12$ & $27.5 \pm 1.21 *$ & $2.52 \pm 0.13$ & $27.4 \pm 1.41 *$ \\
\hline
\end{tabular}

$* P<0.05, * * * P<0.001$ as compared to respective EM incubated in the absence of inhibitor by using one-way ANOVA followed by StudentNewman-Keul's test

Table 2 The effect of inhibitors on the degradation of EMs by DPP IV

\begin{tabular}{|c|c|c|c|c|}
\hline \multirow[t]{3}{*}{ Inhibitor } & \multicolumn{4}{|l|}{ DPP IV } \\
\hline & \multicolumn{2}{|l|}{ EM-1 } & \multicolumn{2}{|l|}{ EM-2 } \\
\hline & Inhibition $(\%)$ & $K_{\mathrm{i}}(\mu \mathrm{M})$ & Inhibition (\%) & $K_{\mathrm{i}}(\mu \mathrm{M})$ \\
\hline Diprotin A & $96.8 \pm 3.27$ & $2.2^{\mathrm{a}}$ & $97.1 \pm 4.00$ & $2.2^{\mathrm{a}}$ \\
\hline Tyr-Pro-Ala-NH ${ }_{2}$ (EMDB-2) & $26.7 \pm 1.20$ & 420 & $44.8 \pm 2.51$ & 170 \\
\hline Tyr-Pro-Ala-OH (EMDB-3) & $39.1 \pm 1.41$ & 270 & $60.0 \pm 2.27$ & 100 \\
\hline
\end{tabular}

${ }^{a}$ Value taken from Ref. Umezawa et al. (1984)

are summarized in Table 2. EMDB-3 appeared to be a better DPP IV inhibitor than EMDB-2. The LineweaverBurk plots revealed that both tested compounds acted as competitive inhibitors of DPP IV (Fig. 3).

Effect of inhibitors on degradation of EMs by APM

EMDB-2 and EMDB-3 were then tested for their inhibitory effect on the degradation of EMs by APM. The known APM inhibitor, actinonin, was included for comparison. Degradation rates and half-lives of EMs alone and in the presence of inhibitors are collected in Table 3. EM-2 was slightly more resistant to APM degradation than EM-1, which is in agreement with earlier data by Peter et al. (1999). Both tested compounds turned out to be better inhibitors of EM degradation by APM than actinonin. The effect of inhibitors on degradation of EMs is summarized in Table 4. The Lineweaver-Burk plots revealed that both new compounds acted as competitive inhibitors of APM (Fig. 4).

\section{Discussion}

The degradation of EMs is responsible for the fact that their analgesic activity decreases in time. Few inhibitors of DPP IV are described in the literature and all of them have limitations in terms of potency, stability or toxicity. Among them diprotin A and diprotin B are probably the best known
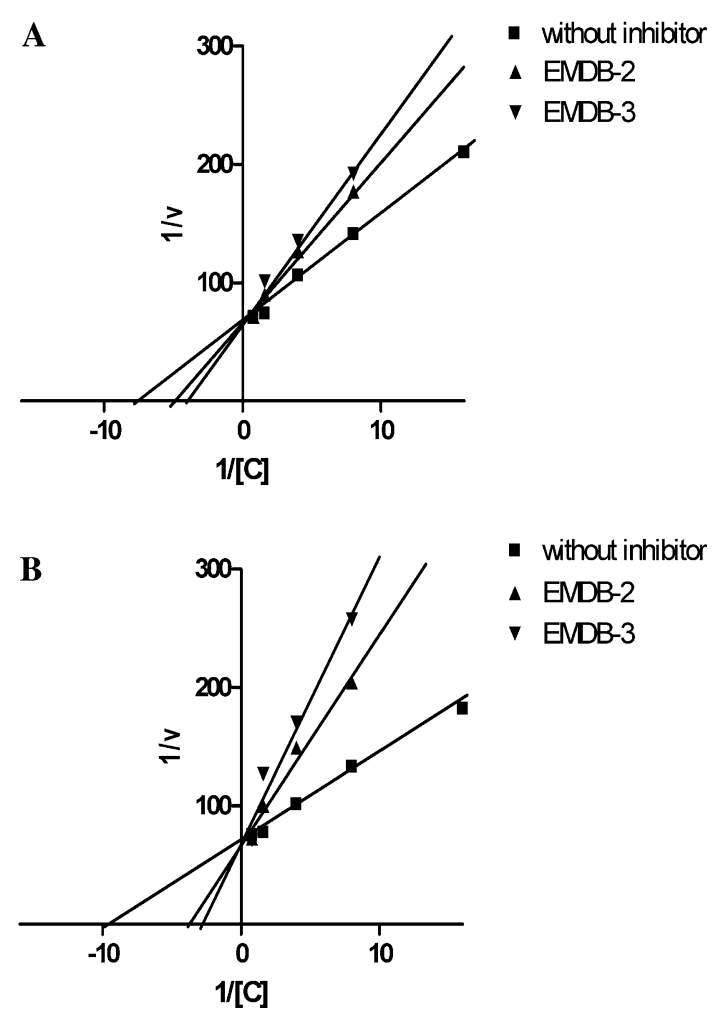

Fig. 3 Lineweaver-Burk diagrams for the inhibition of DPP IV by EMDB-2 and EMDB-3 in case of EM-1 (a) and EM-2 (b)

and commercially available. They are competitive substrates that are slowly hydrolyzed and act as inhibitors for DPP IV at micromolar concentrations (Schon et al., 1991). 
Table 3 Degradation rates $(k)$ and half-lives $\left(t_{1 / 2}\right)$ of EMs incubated with APM alone and in the presence of inhibitors

\begin{tabular}{|c|c|c|c|c|}
\hline \multirow[t]{3}{*}{ Inhibitor } & \multicolumn{4}{|l|}{ APM } \\
\hline & \multicolumn{2}{|l|}{ EM-1 } & \multicolumn{2}{|l|}{ EM-2 } \\
\hline & $100 \times k(1 / \mathrm{min})$ & $t_{1 / 2}(\min )$ & $100 \times k(1 / \mathrm{min})$ & $t_{1 / 2}(\min )$ \\
\hline Without inhibitor & $3.51 \pm 0.09$ & $19.7 \pm 0.50$ & $2.96 \pm 0.12$ & $23.3 \pm 0.98$ \\
\hline Actinonin & $1.88 \pm 0.09$ & $36.8 \pm 2.10^{* * *}$ & $1.50 \pm 0.05$ & $46.3 \pm 1.16^{* *}$ \\
\hline Tyr-Pro-Ala-NH 2 (EMDB-2) & $1.63 \pm 0.06$ & $42.3 \pm 1.89 * * *$ & $1.28 \pm 0.04$ & $53.9 \pm 1.53 * * *$ \\
\hline Tyr-Pro-Ala-OH (EMDB-3) & $1.58 \pm 0.05$ & $43.7 \pm 1.73 * * *$ & $1.44 \pm 0.07$ & $47.9 \pm 2.14^{* * *}$ \\
\hline
\end{tabular}

** $P<0.01$, *** $P<0.001$ as compared to respective EM incubated in the absence of inhibitor by using one-way ANOVA followed by Student-Newman-Keul's test

Table 4 The effect of inhibitors on the degradation of EMs by APM

\begin{tabular}{|c|c|c|c|c|}
\hline \multirow[t]{3}{*}{ Inhibitor } & \multicolumn{4}{|l|}{ APM } \\
\hline & \multicolumn{2}{|l|}{ EM-1 } & \multicolumn{2}{|l|}{ EM-2 } \\
\hline & Inhibition (\%) & $K_{\mathrm{i}}(\mu \mathrm{M})$ & Inhibition (\%) & $K_{\mathrm{i}}(\mu \mathrm{M})$ \\
\hline Actinonin & $46.2 \pm 0.55$ & 390 & $49.3 \pm 0.90$ & 300 \\
\hline Tyr-Pro-Ala-NH ${ }_{2}$ (EMDB-2) & $53.6 \pm 1.21$ & 130 & $56.8 \pm 1.62$ & 80 \\
\hline Tyr-Pro-Ala-OH (EMDB-3) & $55.0 \pm 1.10$ & 100 & $51.4 \pm 1.44$ & 290 \\
\hline
\end{tabular}
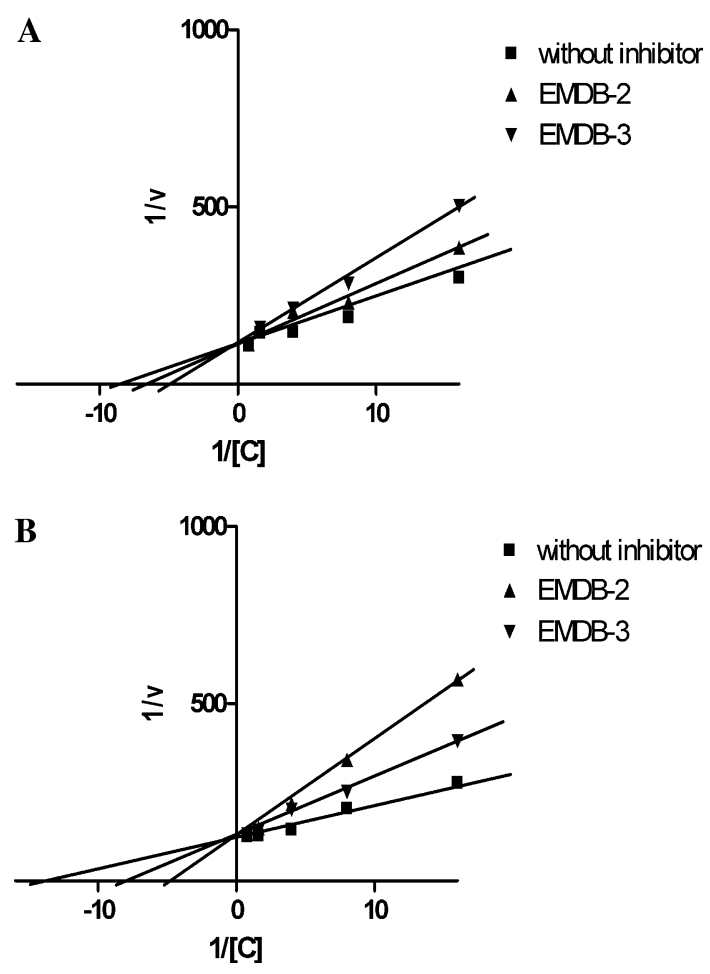

Fig. 4 Lineweaver-Burk diagrams for the inhibition of APM by EMDB-2 and EMDB-3 in case of EM-1 (a) and EM-2 (b)

The most potent DPP IV blockers so far reported are dipeptides containing boroPro, the boronic acid analog of Pro at the C-terminus (Flentke et al., 1991). Although these compounds inhibit DPP IV action at nanomolar concentrations, they are quite unstable and that greatly limits their use. Dipeptide phosphonates described by Boduszek et al. (1994) are irreversible inhibitors of DPP IV, which are specific but not very potent. The series of aminoacylpyrrolidine-2-nitriles obtained by $\mathrm{Li}$ et al. (1995), that have $K_{\mathrm{i}}$ values in the micromolar range, are another group of specific DPP IV inhibitors with good potency and stability.

The studies presented here give evidence that EMDB-2 and EMDB-3 are potent inhibitors of enzymes responsible for EM cleavage. These compounds are stable and easily synthesized. EMDB-2 and EMDB-3 are competitive inhibitors of both, DPP IV and APM, with $K_{\mathrm{i}}$ values in submillimolar range. They are less potent than diprotin A in protecting EMs against DPP IV, but more potent than actinonin in protecting these peptides against APM.

So far we have shown that two new blockers of EM degrading enzymes, EMDB-2 and EMDB-3 significantly prolonged the inhibitory effects of EM-2 in gastrointestinal smooth muscle preparations (Fichna et al., 2010). In vivo studies are under way to establish if these inhibitors can also prolong analgesic effect produced by exogenously administered EMs. Interestingly, preliminary results showed that EMDB-2 and EMDB-3 do not cross the blood-brain barrier, suggesting that their action is limited to the periphery after systemic administration.

Acknowledgments This work was supported by a grant POLONIUM, grants from Polish Ministry of Science Nos. 730/N-POLONIUM/2010/0 and NN 4010064 35, a grant from the Medical University of Lodz No. 503/1-156-02/503-01, and a grant from the Centre National de la Recherche Scientifique (CNRS, France). The 
authors wish to thank Jozef Cieslak for his excellent technical assistance.

Open Access This article is distributed under the terms of the Creative Commons Attribution Noncommercial License which permits any noncommercial use, distribution, and reproduction in any medium, provided the original author(s) and source are credited.

\section{References}

Boduszek B, Oleksyszyn J, Kam Ch-M, Selzler J, Smith RE, Powers JC (1994) Dipeptide phosphonates as inhibitors of dipeptidyl peptidase IV. J Med Chem 37:3969-3976

Czapla MA, Gozal D, Alea OA, Beckerman RC, Zadina JE (2000) Differential cardiorespiratory effects of endomorphin 1, endomorphin 2, DAMGO, and morphine. Am J Respir Crit Care Med 162:994-999

Fichna J, Janecka A, Bailly L, Marsais F, Costentin J, do Rego J-C (2006) In vitro characterization of novel peptide inhibitors of endomorphin-degrading enzymes in the rat brain. Chem Biol Drug Design 68:173-175. doi:10.1111/j.1747-0285.2006.00425.x

Fichna J, Janecka A, Costentin J, do-Rego JC (2007) The endomorphin system and its evolving neurophysiological role. Pharmacol Rev 59:88-123. doi:10.1124/pr.59.1.3

Fichna J, Perlikowska R, Gach K, do-Rego J-C, Cravezic A, Janecka A, Storr MA (2010) The novel endomorphin degradation blockers TyrPro-DClPhe-Phe-NH $\mathrm{NH}_{2}$ (EMDB-1) and Tyr-Pro-Ala- $\mathrm{NH}_{2}$ (EMDB2) prolong endomorphin-2 action in rat ileum in vitro. Chem Biol Drug Des 76:77-81. doi:10.1111/j.1747-0285.2010.00977.x

Flentke GR, Munoz E, Huber BT, Plaut AG, Kettner CA, Bachovchin WW (1991) Inhibition of dipeptidyl aminopeptidase IV (DP-IV) by Xaa-boroPro dipeptides and use of these inhibitors to examine the role of DP-IV in T-cell function. Proc Natl Acad Sci USA 88: $1556-1559$

Fujita T, Kumamoto E (2006) Inhibition by endomorphin-1 and endomorphin- 2 of excitatory transmission in adult rat substantia gelatinosa neurons. Neuroscience 139:1095-1105. doi:10.1016/ j.neuroscience.2006.01.010

Grass S, Xu IS, Wiesenfeld-Hallin Z, Xu X-J (2002) Comparison of the effect of intrathecal endomorphin-1 and endomorphin-2 on spinal cord excitability in rats. Neurosci Lett 324:197-200. doi: 10.1016/S0304-3940(02)00201-X

Horvath G (2000) Endomorphin-1 and endomorphin-2: pharmacology of the selective endogenous $\mu$-opioid receptor agonist. Pharmacol Ther 88:437-463. doi:10.1016/S0163-7258(00)00100-5

Horvath G, Szikszay M, Tomboly C, Benedek G (1999) Antinociceptive effects of intrathecal endomorphin-1 and -2 in rats. Life Sci 65:2635-2641. doi:10.1016/S0024-3205(99)00532-9
Keresztes A, Borics A, Tóth G (2010) Recent advances in endomorphin engineering. Chem Med Chem. doi:10.1002/cmdc.201000077

Li J, Wilk E, Wilk S (1995) Aminoacylpyrrolidine-2-nitriles: potent and stable inhibitors of dipeptidyl-peptidase IV (CD 26). Arch Biochem Biophys 323:148-154. doi:10.1006/abbi.1995.0020

Mentlein R (1999) Dipeptidyl-peptidase IV (CD26)-role in the inactivation of regulatory peptides. Regul Pept 85:9-24. doi: 10.1016/S0167-0115(99)00089-0

Narita M, Mizoguchi H, Oji DE, Dun NJ, Hwang BH, Nagase H, Tseng LF (1999) Identification of the G-protein-coupled ORL1 receptor in the mouse spinal cord by [35S]-GTPgammaS binding and immunohistochemistry. Br J Pharmacol 128:1300-1306

Peter A, Toth G, Tomboly C, Laus G, Tourwe D (1999) Liquid chromatographic study of the enzymatic degradation of endomorphins, with identification by electrospray ionization mass spectrometry. J Chromatogr A 846:39-48

Przewłocki R, Przewłocka B (2001) Opioids in chronic pain. Eur J Pharmacol 429:79-91. doi:10.1016/S0014-2999(01)01308-5

Sakurada C, Sakurada S, Hayashi T, Katsuyama S, Tan-No K, Sakurada T (2003) Degradation of endomorphin-2 at the supraspinal level in mice is initiated by dipeptidyl peptidase IV: an in vitro and in vivo study. Biochem Pharmacol 66:653-661. doi:10.1016/S0006-2952(03)00391-5

Schon E, Born I, Demuth HU, Faust J, Neubert K, Steinmetzer T, Barth A, Ansorge S (1991) Dipeptidyl peptidase IV in the immune system. Effects of specific enzyme inhibitors on activity of dipeptidyl peptidase IV and proliferation of human lymphocytes. Biol Chem Hoppe Seyler 372:305-311

Shane R, Wilk S, Bodnar RJ (1999) Modulation of endomorphin-2induced analgesia by dipeptidyl peptidase IV. Brain Res 815:278-286. doi:10.1016/S0006-8993(98)01121-4

Sugimoto-Watanabe A, Kubota K, Fujibayashi K, Saito K (1999) Antinociceptive effect and enzymatic degradation of endomorphin-1 in newborn rat spinal cord. Jpn J Pharmacol 81:264-270

Tomboly C, Peter A, Toth G (2002) In vitro quantitative study of the degradation of endomorphins. Peptides 23:1573-1580. doi: 10.1016/S0196-9781(02)00100-6

Umezawa H, Aoyagi T, Ogawa K, Naganawa H, Hamada M, Takeuchi T (1984) Diprotin A and B, inhibitors of dipeptidyl aminopeptidase IV, produced by bacteria. J Antibiot 37:422-425

Wilson AM, Soignier RD, Zadina JE, Kastin AJ, Nores WL, Olson RD, Olson GA (2000) Dissociation of analgesic and rewarding effects of endomorphin-1 in rats. Peptides 20:1871-1874. doi: 10.1016/S0196-9781(00)00340-5

Zadina JE, Hackler L, Ge J-L, Kastin AJ (1997) A potent and selective endogenous agonist for the mu-opiate receptor. Nature 386:499-502. doi:10.1038/386499a0 